\title{
Radiographic assessment of symptomatic knee osteoarthritis in the community: definitions and normal joint space
}

\author{
Peter Lanyon, Sheila O’Reilly, Adrian Jones, Michael Doherty
}

\begin{abstract}
Objective-To evaluate radiographic features of osteoarthritis (OA) to determine which is more closely associated with knee pain and hence might be used as a radiographic definition of $\mathrm{OA}$ in the community. To evaluate joint space width in normal subjects.

Methods-452 subjects from a case-control community study of knee pain (294 women, 158 men, mean age 62 years, range 40-80) underwent AP standing and midflexion skyline radiographs. Joint space width, measured by metered calliper to 0.1 $\mathrm{mm}$, and graded individual features of $O A$ (osteophyte $0-3$, narrowing $0-3$, sclerosis $0-1$, cysts $0-1$ ) were assessed in all three compartments independently by two observers who were blind to clinical status. Subjects were categorised as having knee pain by a positive response to both parts of the question "Have you ever had pain in or around the knee on most days for at least a month? If so, have you experienced any pain during the last year?"
\end{abstract}

Results-Intraobserver reproducibility for joint space width measurements was to within $\pm 0.4 \mathrm{~mm}(95 \%$ CI for limits of agreement); $\kappa$ values for grading were $>0.7$. One hundred and twenty five subjects were without knee pain or osteophyte. In these radiographically normal knees, mean joint space width varied according to sex but did not decrease with age. A definition based on the presence of osteophyte $\geqslant$ grade 1 in any compartment was more efficient at predicting pain than definitions based on either measurement or grading of joint space; there was no clear threshold of joint space loss at which the likelihood of pain substantially increased. The presence of osteophyte at the patellofemoral joint (PFJ) was more sensitive but less specific than at the tibiofemoral joint (TFJ); the addition of PFJ assessment improved sensitivity from $38.1 \%$ to $62.3 \%$ with a reduction in specificity from $82.7 \%$ to $58.7 \%$ for the presence of knee pain.

Rheumatology Unit, City Hospital, Hucknall Road, Nottingham NG5 1PB

Correspondence to: Dr P Lanyon.

Accepted for publication 6 August 1998 a feature of asymptomatic aging, and there is not a biological cut off for joint the community, osteophyte is the radiographic feature that associates best with knee pain. Radiographic assessment of both TFJ and PFJ should be included in all space width below which the likelihood of knee pain markedly increases.

(Ann Rheum Dis 1998;57:595-601)

Osteoarthritis (OA) of the knee is a major cause of disability in the community and imposes significant economic costs upon society. Estimated population prevalence varies from $4-30 \%$, depending on the age, sex distribution, and disease definition. ${ }^{1}$ While all clinicians may know what constitutes OA, epidemiological and outcome studies have been hampered by lack of agreement on a precise definition. This has partly reflected a desire for an all embracing definition that includes the three domains that we associate with OA: pain, disability, and structural change. However, there is discordance between these domains. For example, only $40-80 \%$ of subjects with radiographic knee OA have symptoms. ${ }^{2}$ Most researchers have concentrated on definitions based on aspects of structural change visualised on plain radiographs. Ideally, any such definition should be reproducible, accurate, and associated with knee pain, but there remains controversy as to which radiological features should be used to define knee OA, particularly in the community.

The radiographic grading system of Kellgren and Lawrence, ${ }^{3}$ variations of which have been used in most epidemiological studies, emphasises the presence of osteophyte. More recent studies have also re-emphasised the importance of osteophyte in definition. ${ }^{4}$ However, radiographic assessment of the patellofemoral compartment, a site commonly affected by $\mathrm{OA}^{6}{ }^{6}$ has often been excluded. When this assessment has been included, it has mainly been from lateral view radiographs, ${ }^{4}$ which are less sensitive at measuring joint space loss than skyline views. ${ }^{89}$ The importance of joint space narrowing may be underestimated because of a lower sensitivity of visual grading compared with direct measurement. Additionally, some community studies have been undertaken among the female population and it is not known how generalisable these results are to men, given the higher prevalence of symptoms in women for a given radiographic change. ${ }^{10}$

The importance of osteophyte in defining $\mathrm{OA}$ at the knee is in contrast with the hip, where definitions based on minimum joint space have been proposed. ${ }^{11}{ }^{12}$ These proposals have been facilitated by knowledge of joint space width in asymptomatic subjects without disease. ${ }^{13-15}$ In contrast, there is a paucity of data on the range of tibiofemoral and 
Table 1 Number of subjects with each maximum osteophyte or narrowing grade in either TFF or PFF according to presence of knee pain

\begin{tabular}{lrl}
\hline Maximum osteophyte grade & No knee pain & Knee pain \\
\hline 0 & 125 & 90 \\
1 & 72 & 78 \\
2 & 11 & 43 \\
3 & 5 & 28 \\
Maximum narrowing grade & & \\
0 & 113 & 90 \\
1 & 76 & 82 \\
2 & 17 & 23 \\
3 & 7 & 44 \\
\end{tabular}

patellofemoral joint space in asymptomatic people. One previous study of subjects attending an Accident and Emergency Department with knee pain or trauma reported a reduction in tibiofemoral joint space with age. ${ }^{16}$

The aims of this study were to examine different radiological features of osteoarthritis and their association with pain and to establish a range for knee joint space widths among asymptomatic subjects in a large community study of men and women.

\section{Methods}

The local research ethics committee granted approval for this study.
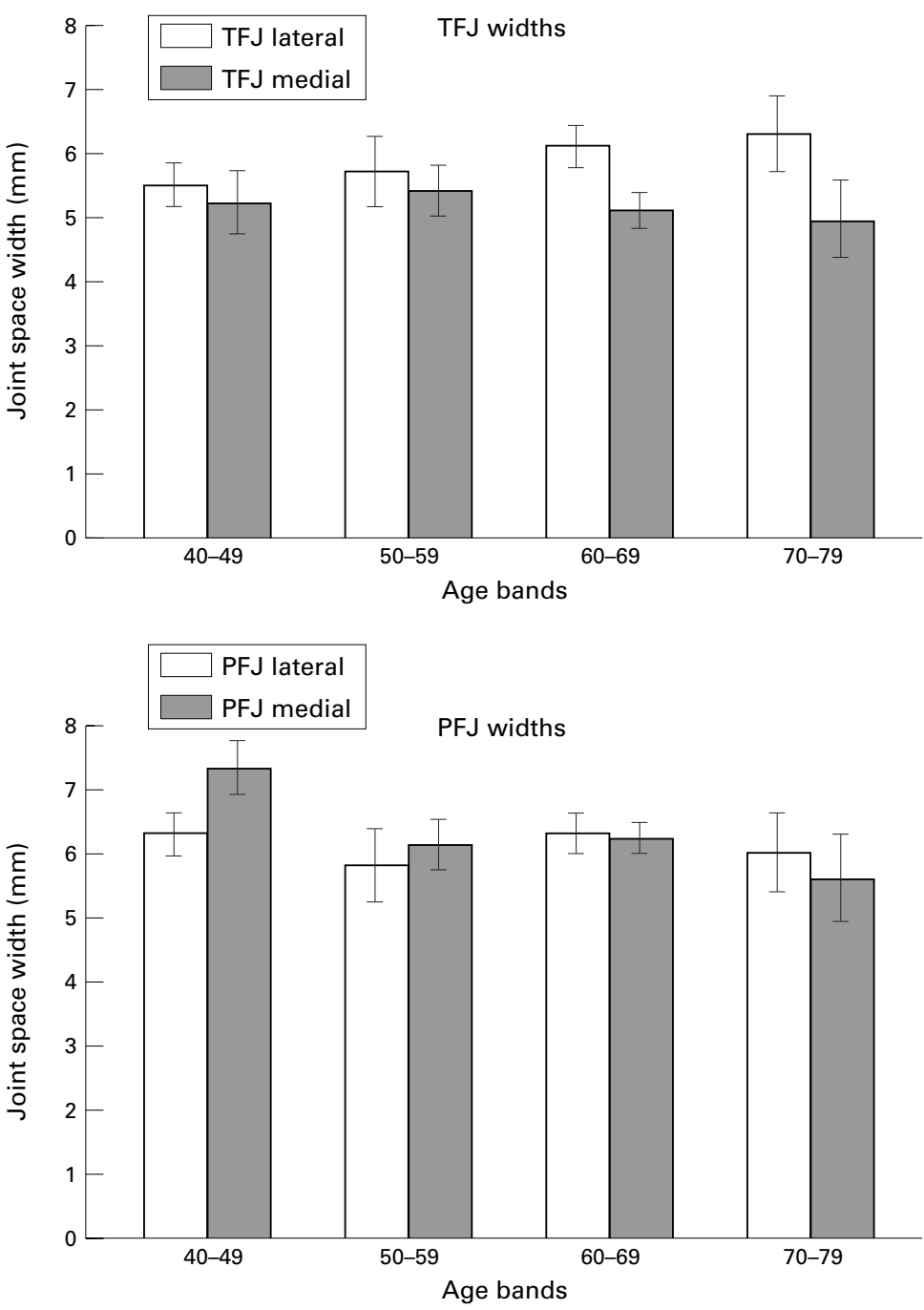

Figure 1 Minimum joint space width (95\% CI) in men for medial and lateral TFF and PFf compartments.
SUBJECTS

Subjects comprised 294 women and 158 men (mean age 62 years, range 40-80) derived from a case-control community study. This involved a postal questionnaire survey to 4000 people (selected by random sampling, stratified by age from the lists of two general practices in Nottingham) inquiring, among other things, about knee pain. For subjects to be designated as "knee pain" positive, a positive response was required to both parts of the question

(a) "Have you ever had pain in or around the knee on most days for at least a month?

(b) If so, have you experienced any pain during the last year?" 17

A negative response to both parts of the above question was designated as "knee pain" negative. The subject's designation (knee pain positive or negative) was hence assigned to both knees. Subjects who were knee pain positive were age and sex matched to a subject from the same general practice who was knee pain negative and invited to attend for a clinical examination including height and weight estimation and plain radiography.

\section{RADIOGRAPHS}

Standardised AP (weightbearing, full extension, $55 \mathrm{kV}, 8 \mathrm{~mA} / \mathrm{s}$, FSD $100 \mathrm{~cm}$ ) and skyline radiographs (mid-flexion, according to method of Laurin, ${ }^{18} 60 \mathrm{kV}, 10 \mathrm{~mA} / \mathrm{s}$, FSD $100 \mathrm{~cm}$ ) of both knees were available for all subjects. A single observer graded narrowing and osteophyte $0-3$, according to a standard atlas. ${ }^{19}$ On a separate occasion, a second observer independently measured joint space in the medial and lateral compartments of the tibiofemoral (TFJ) and patellofemoral (PFJ) joints of both knees by hand to the nearest $0.1 \mathrm{~mm}$ using a metered dial calliper (RS Components, Switzerland). On the skyline view, minimum joint space in each facet was measured from the bright radiodense band of subchondral cortex on the patella to the articular margin of the femoral cortex..$^{20}$ On the AP view, measurements of minimum joint space were made in each compartment using recommended landmarks. ${ }^{20}$ Both observers were blind to each other's assessment and the knee pain status of the patient.

\section{STATISTICS}

To assess reproducibility 40 subjects were rescored for all measurements by the original observers one week after initial assessment. Level of agreement for grading was quantified using the $\kappa$ statistic $^{21}$; reproducibility of continuous variables was assessed using the method of Bland and Altman. ${ }^{22}$ Confidence intervals and correlation coefficients were calculated according to standard methods. ${ }^{23}$ Odds ratios for pain were calculated for different cut off levels of abnormality (for example, grade 1 and above $v$ grade 0 , grade 2 and above $v$ grades $0-1$, grade $3 v$ grades $0-2$ ). All analyses included both knees from each subject, except for the association of graded individual features and measured joint space width with pain, where the maximum grade or minimum joint space in either knee for each specified 

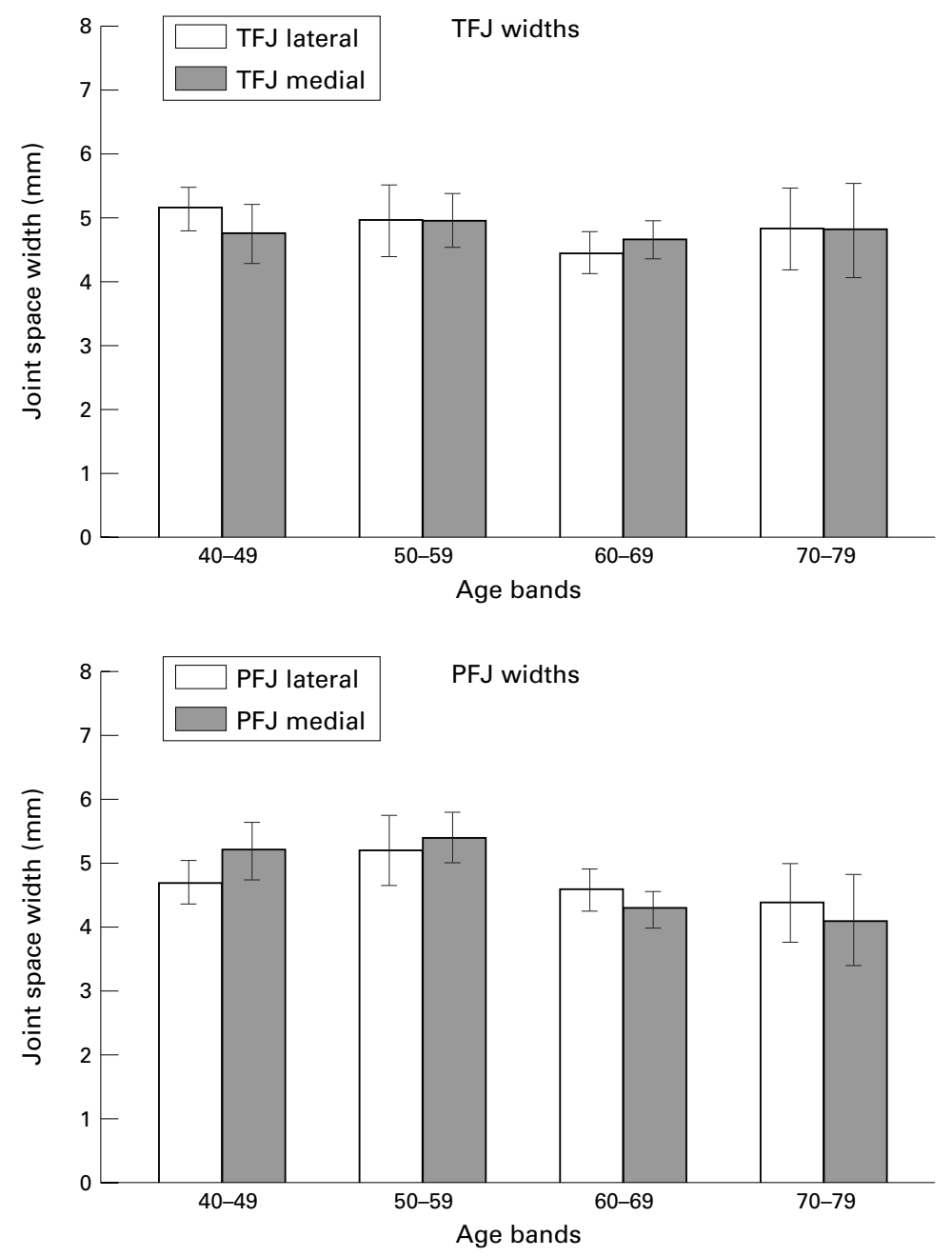

Figure 2 Minimum joint space width $(95 \%$ CI) in women for lateral and medial TFF and PFf compartments. urements of minimum joint space and was similar at all sites (PFJ medial $\pm 0.36 \mathrm{~mm}$, lateral $\pm 0.41 \mathrm{~mm}$; TFJ medial $\pm 0.44 \mathrm{~mm}$, lateral $\pm 0.44 \mathrm{~mm}$ ). Interobserver reproducibility for grading from the atlas was good at all sites ( $\kappa$ values $>0.7$ ).

RADIOGRAPHS

The case-control study comprised 239 subjects with knee pain (53\%) and 213 subjects (47\%) without pain. Eight seven subjects (19\%) had $\geqslant$ grade 2 osteophyte in any compartment in either knee (60 PFJ, $57 \mathrm{TFJ})$ and 91 subjects $(20 \%)$ had $\geqslant$ grade 2 narrowing in any compartment (59 PFJ, 43 TFJ). Table 1 shows the number of subjects with each maximum osteophyte or narrowing grade in either TFJ or PFJ according to the presence of knee pain.

JOINT SPACE IN “NORMAL” SUBJECTS

One hundred and twenty five subjects were without knee pain or osteophyte in any compartment, and were designated as having radiographically "normal" knees. This group comprised 86 women and 39 men, of mean age 58 years, range 40-75. Mean joint space widths, according to age and sex, are shown in figures 1 (men) and 2 (women). Mean values were generally higher in men than women. In both sexes there was no significant decline in joint space in any compartment with increasing age. There was no significant correlation between joint space and height, weight or body mass index.

ASSOCIATION OF GRADED RADIOGRAPHIC

FEATURES WITH PAIN

The association of individual radiographic features with pain at single and combined sites is shown in table 2 (joint space narrowing) and table 3 (osteophyte). Odds ratios for pain (95\% CI) are shown according to the level at which features are dichotomised (for example, grade 1 and above $v$ grade 0 , grade 2 and above $v$ grade $0-1$, etc). The cut off levels shown represent the maximum grade in either knee (that is, the worst knee) for each specified compartment. Efficiency was computed from (sensitivity

\section{Results}

REPRODUCIBILITY

Interobserver reproducibility was to within $\pm 0.4 \mathrm{~mm}$ ( $95 \%$ limits of agreement) for meas- narrowing. Odds ratios (OR) for pain are for different cut off levels of abnormality (for example, $\geqslant$ grade 1 v grade 0 , etc)

\begin{tabular}{|c|c|c|c|c|c|}
\hline Site & Grade & $\begin{array}{l}\text { OR for pain } \\
(95 \% \text { CI) }\end{array}$ & $\begin{array}{l}\text { Sensitivity } \\
(\%)\end{array}$ & $\begin{array}{l}\text { Specificity } \\
(\%)\end{array}$ & $\begin{array}{l}\text { Efficiency } \\
(\%)\end{array}$ \\
\hline \multirow[t]{3}{*}{ PFJ lateral } & $\geqslant 1$ & $2.5(1.5,4.1)$ & 24.7 & 88.3 & 56.5 \\
\hline & $\geqslant 2$ & $4.4(2.0,9.7)$ & 14.6 & 96.3 & 55.5 \\
\hline & $\geqslant 3$ & $12.9(3.0,55.0)$ & 10.8 & 91.1 & 50.9 \\
\hline \multirow[t]{3}{*}{ PFJ medial } & $\geqslant 1$ & $1.1(0.6,1.8)$ & 15.9 & 85 & 50.5 \\
\hline & $\geqslant 2$ & $1.2(0.5,2.7)$ & 5.4 & 95.3 & 50.4 \\
\hline & $\geqslant 3$ & $0.9(0.3,3.1)$ & 2.0 & 97.7 & 49.9 \\
\hline \multirow[t]{3}{*}{ Maximum PFJ grade } & $\geqslant 1$ & $1.8(1.2,2.8)$ & 32.6 & 79.9 & 56.3 \\
\hline & $\geqslant 2$ & $2.7(1.5,4.9)$ & 17.9 & 92.5 & 55.2 \\
\hline & $\geqslant 3$ & $4.1(1.7,9.5)$ & 12.1 & 96.7 & 54.4 \\
\hline \multirow[t]{3}{*}{ TFJ lateral } & $\geqslant 1$ & $0.8(0.5,1.3)$ & 12.9 & 84.1 & 48.5 \\
\hline & $\geqslant 2$ & $2.3(0.4,11.7)$ & 2.1 & 91.1 & 46.6 \\
\hline & $\geqslant 3$ & $\star$ & 1.7 & 100 & 50.9 \\
\hline \multirow[t]{3}{*}{ TFJ medial } & $\geqslant 1$ & $2.1(1.4,3.1)$ & 38.9 & 76.6 & 57.8 \\
\hline & $\geqslant 2$ & $5.3(2.2,13.0)$ & 13.4 & 97.2 & 55.3 \\
\hline & $\geqslant 3$ & $\star$ & 6.7 & 100 & 53.4 \\
\hline \multirow[t]{3}{*}{ Maximum TFJ grade } & $\geqslant 1$ & $1.9(1.3,2.8)$ & 48.5 & 67.2 & 57.9 \\
\hline & $\geqslant 2$ & $4.4(2.0,9.7)$ & 14.6 & 96.3 & 55.5 \\
\hline & $\geqslant 3$ & $\star$ & 7.9 & 100 & 53.9 \\
\hline \multirow[t]{3}{*}{ Maximum grade whole knee } & $\geqslant 1$ & $1.8(1.3,2.7)$ & 62.3 & 53.1 & 57.7 \\
\hline & $\geqslant 2$ & $3.1(1.8,5.1)$ & 28.0 & 78.8 & 53.4 \\
\hline & $\geqslant 3$ & $6.6(2.9,15.1)$ & 18.4 & 96.7 & 57.6 \\
\hline
\end{tabular}


Table 3 Association of pain with site and grade of osteophyte. Odds ratios (OR) for pain are for different cut off levels of abnormality (for example, $\geqslant$ grade 1 vrade 0 , etc)

\begin{tabular}{|c|c|c|c|c|c|}
\hline Site & Grade & $\begin{array}{l}\text { OR for pain } \\
(95 \% \text { CI) }\end{array}$ & $\begin{array}{l}\text { Sensitivity } \\
(\%)\end{array}$ & $\begin{array}{l}\text { Specificity } \\
(\%)\end{array}$ & $\begin{array}{l}\text { Efficiency } \\
(\%)\end{array}$ \\
\hline \multirow[t]{3}{*}{ PFJ lateral } & $\geqslant 1$ & $2.7(1.9,4.1)$ & 51.2 & 71.9 & 61.6 \\
\hline & $\geqslant 2$ & $5.6(2.4,12.8)$ & 12.9 & 96.8 & 54.9 \\
\hline & $\geqslant 3$ & $5.6(1.2,25.2)$ & 5.0 & 99.1 & 52.1 \\
\hline \multirow[t]{3}{*}{ PFJ medial } & $\geqslant 1$ & $3.2(2.1,4.8)$ & 45.2 & 79.4 & 62.3 \\
\hline & $\geqslant 2$ & $11.7(2.7,50.5)$ & 10.0 & 99.1 & 54.6 \\
\hline & $\geqslant 3$ & $\star$ & 0.4 & 100 & 50.2 \\
\hline \multirow[t]{3}{*}{ Maximum PFJ grade } & $\geqslant 1$ & $2.6(1.8,3.8)$ & 58.9 & 64.3 & 61.6 \\
\hline & $\geqslant 2$ & $6.1(2.9,12.8)$ & 21.3 & 95.8 & 58.6 \\
\hline & $\geqslant 3$ & $6.1(1.4,27.2)$ & 5.4 & 99.1 & 52.3 \\
\hline \multirow[t]{3}{*}{ TFJ medial tibial } & $\geqslant 1$ & $3.2(1.7,5.3)$ & 19.7 & 93 & 56.4 \\
\hline & $\geqslant 2$ & $18.3(2.4,137)$ & 7.9 & 99.5 & 53.7 \\
\hline & $\geqslant 3$ & $\star$ & 1.2 & 100 & 50.6 \\
\hline \multirow[t]{3}{*}{ TFJ lateral tibial } & $\geqslant 1$ & $3.9(1.9,7.8)$ & 17.6 & 94.9 & 56.3 \\
\hline & $\geqslant 2$ & $16.2(2.1,123.0$ & 7.1 & 99.5 & 53.3 \\
\hline & $\geqslant 3$ & $5.5(0.6,45.7)$ & 2.5 & 99.5 & 51.0 \\
\hline \multirow[t]{3}{*}{ TFJ medial femoral } & $\geqslant 1$ & $3.0(1.7,5.3)$ & 21.7 & 91.6 & 56.7 \\
\hline & $\geqslant 2$ & $7.8(2.7,24.50$ & 12.9 & 98.2 & 55.6 \\
\hline & $\geqslant 3$ & $10.2(1.3,79.9)$ & 4.6 & 95.5 & 50.1 \\
\hline \multirow[t]{3}{*}{ TFJ lateral femoral } & $\geqslant 1$ & $2.6(1.5,4.5)$ & 20.1 & 91.1 & 55.6 \\
\hline & $\geqslant 2$ & $4.3(1.4,12.8)$ & 7.5 & 98.2 & 52.9 \\
\hline & $\geqslant 3$ & $3.6(0.4,32.5)$ & 1.6 & 95.5 & 48.6 \\
\hline \multirow[t]{3}{*}{ Maximum TFJ grade } & $\geqslant 1$ & $2.9(1.9,4.5)$ & 38.1 & 82.7 & 60.4 \\
\hline & $\geqslant 2$ & $6.6(3.1,14.3)$ & 20.5 & 96.3 & 58.4 \\
\hline & $\geqslant 3$ & $6.0(1.8,20.7)$ & 7.9 & 98.6 & 53.3 \\
\hline \multirow[t]{3}{*}{ Maximum grade whole knee } & $\geqslant 1$ & $2.5(1.6,3.4)$ & 62.3 & 58.7 & 60.5 \\
\hline & $\geqslant 2$ & $5.2(2.9,9.3)$ & 29.7 & 92.5 & 61.1 \\
\hline & $\geqslant 3$ & $5.5(2.1,14.6)$ & 11.1 & 97.7 & 54.4 \\
\hline
\end{tabular}

${ }^{\star}$ Denominator zero therefore unable to calculate simple odds ratios.

+ specificity)/2. There were positive associations between pain and the presence of osteophyte at any joint site, with a stronger association at increasing grades. However, for narrowing, all associations were generally less marked. Also, the association varies considerably according to the site of narrowing. For example, while narrowing of all grades in the lateral PFJ facet is strongly associated with pain, there was no association between pain and narrowing in the medial facet. Likewise, at the TFJ, the association with pain is much stronger for narrowing in the medial compartment compared with lateral.
Definitions based on the presence of $\geqslant$ grade 1 narrowing (in either medial or lateral compartments) had greater specificity $(79.9 \%)$ but less sensitivity $(32.6 \%)$ when this feature was present in PFJ compared with the TFJ view (specificity $67.2 \%$, sensitivity $48.5 \%)$. In contrast, a similar definition based on the presence of $\geqslant$ grade 1 osteophyte had greater specificity $(82.7 \%)$ but less sensitivity (38.1\%) when present in the TFJ compared with the PFJ (specificity $64.3 \%$, sensitivity $58.9 \%$ ). Definition based on the presence of either $\geqslant$ grade 1 osteophyte or $\geqslant$ grade 1 narrowing in any joint had similar sensitivity

Table 4 Association between pain and measured joint space width (mm). Odds ratios (OR) for pain are for different cut off levels of abnormality (for Table 4 Association between
example, $\leqslant 2 m m v>2 m m$ )

\begin{tabular}{|c|c|c|c|c|c|c|c|c|c|c|c|}
\hline Width (mm) & 0 & 1 & 2 & 3 & 4 & 5 & 6 & 7 & 8 & 9 & 10 \\
\hline \multicolumn{12}{|l|}{ PFJ lateral } \\
\hline OR & 8.9 & 6.9 & 5.5 & 2.9 & 1.7 & 1.1 & 1.4 & 1.6 & 0 & 0 & * \\
\hline Sensitivity & 11.3 & 14.2 & 17.5 & 25.1 & 36.8 & 56.6 & 86.2 & 97.9 & 98.7 & 99.1 & 100 \\
\hline Specificity & 98.5 & 97.6 & 96.2 & 89.6 & 74.1 & 44.6 & 17.8 & 3.2 & 0 & 0 & 0 \\
\hline Efficiency & 54.9 & 56.9 & 56.9 & 57.3 & 55.4 & 55.6 & 52 & 50.5 & 49.3 & 49.5 & 50 \\
\hline \multicolumn{12}{|l|}{ PFJ medial } \\
\hline OR & 1.2 & 1.3 & 1.5 & 1.0 & 0.8 & 0.8 & 0.7 & 0.8 & 2.2 & 1.2 & $\star$ \\
\hline Sensitivity & 5.0 & 5.8 & 8.7 & 17.1 & 31.3 & 53.5 & 74.8 & 91.6 & 98.7 & 99.5 & 100 \\
\hline Specificity & 95.7 & 95.3 & 93.8 & 83.0 & 65.2 & 41.3 & 19.7 & 7.5 & 2.8 & 0.4 & 0 \\
\hline Efficiency & 50.4 & 50.5 & 51.3 & 50.1 & 48.3 & 47.4 & 47.2 & 49.5 & 50.7 & 49.9 & 50 \\
\hline \multicolumn{12}{|l|}{ TFJ lateral } \\
\hline OR & 3.6 & 3.6 & 1.4 & 0.9 & 0.6 & 0.7 & 0.7 & 0.5 & 0.4 & 1.1 & 0 \\
\hline Sensitivity & 1.6 & 1.6 & 3.3 & 7.5 & 19.2 & 51.4 & 81.1 & 94.9 & 98.7 & 99.5 & 100 \\
\hline Specificity & 99.5 & 99.5 & 97.6 & 91.5 & 69.9 & 40.3 & 14.0 & 2.8 & 0.4 & 0.4 & 0 \\
\hline Efficiency & 50.5 & 50.5 & 50.4 & 49.5 & 44.5 & 45.8 & 47.5 & 48.8 & 49.5 & 50 & 50 \\
\hline \multicolumn{12}{|l|}{ TFJ medial } \\
\hline OR & $\star$ & $\star$ & 29.2 & 4.5 & 2.0 & 1.1 & 0.7 & 0.3 & 1.1 & 0 & 0 \\
\hline Sensitivity & 5.0 & 7.5 & 12.1 & 16.7 & 39.7 & 75.7 & 91.1 & 98.3 & 99.5 & 99.5 & 99.5 \\
\hline Specificity & 100 & 100 & 99.5 & 95.7 & 75.5 & 26.2 & $6.1^{6}$ & 0.5 & 0.5 & 0 & 0 \\
\hline Efficiency & 52.5 & 53.5 & 55.8 & 56.2 & 57.6 & 50.9 & 48.8 & 49.2 & 50 & 49.8 & 49.8 \\
\hline \multicolumn{12}{|l|}{ PFJ narrowest } \\
\hline OR & 3.0 & 3.3 & 3.0 & 1.7 & 1.2 & 1.0 & 1.1 & 1.1 & 0 & $\star$ & $\star$ \\
\hline Sensitivity & 12.9 & 16.3 & 21.7 & 32.2 & 48.1 & 69.0 & 90.3 & 99.1 & 99.5 & 100 & 100 \\
\hline Specificity & 95.3 & 94.3 & 91.5 & 77.9 & 56.3 & 31.9 & 10.3 & 0.9 & 0 & 0 & 0 \\
\hline Efficiency & 49.3 & 50.1 & 51.0 & 50.6 & 49.1 & 47.7 & 48.8 & 50.0 & 50 & 50 & 50 \\
\hline \multicolumn{12}{|l|}{ TFJ narrowest } \\
\hline OR & 13.2 & 19.3 & 5.5 & 2.1 & 1.3 & 1.0 & 1.4 & 夫 & 夫 & 夫 & $\star$ \\
\hline Sensitivity & 5.8 & 8.3 & 13.8 & 22.1 & 50.2 & 86.1 & 98.3 & 100 & 100 & 100 & 100 \\
\hline Specificity & 99.5 & 99.5 & 97.1 & 88.2 & 56.8 & 13.6 & 2.3 & 0 & 0 & 0 & 0 \\
\hline Efficiency & 52.6 & 53.9 & 55.5 & 55.2 & 53.5 & 49.8 & 50.3 & 50 & 50 & 50 & 50 \\
\hline
\end{tabular}

$\star$ Denominator zero therefore unable to calculate simple odds ratios. 
$(62.3 \%)$, but the specificity was slightly higher for osteophyte $(58.7 \%)$ than narrowing (53.1\%).

Despite these differences in sensitivity and specificity, the efficiency of definitions based on either narrowing or osteophyte did not differ by joint site. Overall, the efficiency of definitions based on the presence of $\geqslant$ grade 1 osteophyte on any view $(60.5 \%)$ were slightly higher than a similar definition based on narrowing $(57.7 \%)$. Moving to a stricter definition requiring the presence of $\geqslant$ grade 2 features did not improve efficiency.

ASSOCIATION OF JOINT SPACE MEASUREMENTS WITH PAIN

Table 4 shows the associations between pain and joint space width; odds ratios were calculated for different measurement cut off levels (for example, $\leqslant 2 \mathrm{~mm} v>2 \mathrm{~mm}$ ), which represent the minimum joint space width in either knee (that is, the worst knee) for each specified compartment. In general, these results are similar to those for graded narrowing, with the strongest associations between pain and joint space width being found in the lateral PFJ and medial TFJ compartments. All medial PFJ widths were only weakly associated with pain, with, paradoxically, the strongest associations with pain found at $>8 \mathrm{~mm}$. Receiver operating characteristic (ROC) curves were plotted for each measure and did not suggest a cut off threshold for joint space width that would be a useful definition (data not shown). We also attempted to define a cut off based on the joint space measurements in subjects with radiographically normal knees. Choosing a definition of $\leqslant 4 \mathrm{~mm}$ in the lateral PFJ, (based on the lowest $95 \%$ CI for normal joint space in this compartment) had a specificity of $74.1 \%$ and sensitivity of $36.8 \%$. Narrowing this definition to $\leqslant 3 \mathrm{~mm}$ resulted in an increase in specificity $(89 \%)$ and a decrease in sensitivity $(25 \%)$, with a small increase in efficiency from $55.4 \%$ to $57.3 \%$. A similar definition based on width $\leqslant 4 \mathrm{~mm}$ in the medial tibiofemoral compartment had a specificity of $75.5 \%$ and sensitivity $39.7 \%$ : reducing the width to $\leqslant 3 \mathrm{~mm}$ resulted in decreased efficiency from 57.6 to $56.2 \%$. The efficiency of definitions based on joint space in other compartments (medial PFJ or lateral TFJ) was generally less, which may be a reflection of greater difficulty in assessing joint space width in these compartments.

Overall, the efficiency of definitions based on joint space narrowing in any joint was not improved by using measurement of joint space width rather than grading, and remained less efficient than definitions based on osteophyte.

\section{Discussion}

We have demonstrated that among asymptomatic subjects without knee osteophyte there is no reduction in mean joint space width with age. This result is in contrast with the findings of a previous study, ${ }^{16}$ which suggested that joint space width decreases with age until a symptomatic pain threshold is reached. These conflicting results are likely to be caused by differences in subject selection. The previous study, among subjects who had attended an Accident and Emergency Department, included a large proportion with knee pain, judged not to have clinical evidence of arthritis on examination, who were assessed by non-weightbearing anteroposterior films. ${ }^{16}$ We accept that our subjects, who have never had knee pain and have no evidence of osteophytosis, are a highly selected group, results from which may not be generalisable to all subjects in the community. Also, "true" joint space loss with age cannot be determined from a cross sectional study. Nevertheless, the finding that joint space does not necessarily decrease with age among asymptomatic subjects is in keeping with the concept that OA is a specific process and not an inevitable part of aging or "wear and tear".

The associations between radiographic change and pain suggest that a definition based on the presence of $\geqslant$ grade 1 osteophyte in any compartment is the most efficient method with which to define radiographic knee $\mathrm{OA}$ in the community. Although this finding is in agreement with most previous studies, many of these have either not been performed in the community, have not included men, or have not optimally visualised the patellofemoral compartment. ${ }^{457}$ It is possible that some of these factors may influence the performance of joint space narrowing. The American College of Rheumatology (ACR) classification criteria, reliant on knee pain and osteophytosis, was derived from analysis of hospital patients using discrimination from a group of predominately RA subjects, whom may have had joint space narrowing consequent to this disease. ${ }^{5}$ A large community study of middle aged women reported osteophyte to be a better method of defining knee OA than joint space narrowing assessed by either grade or direct measurement. ${ }^{4}$ However, this study did not include assessment of the PFJ and used an arbitrary dichotomisation for all scoring variables made at the 10th centile of their sample distribution, a cut off chosen to be similar to the estimated radiographic population prevalence. A further study of 250 women, which did include patellofemoral assessment, by grading only, reached a similar conclusion. ${ }^{24}$ We undertook measurement of both PFJ and TFJ width and dichotomised these measurements based on their distribution in asymptomatic subjects without osteophyte. Despite these refinements, we have not been able to demonstrate that assessment of narrowing by joint space measurement performs any better than simple visual grading alone in predicting knee pain. The presence of narrowing assessed by either method is less efficient at predicting knee pain than the presence of osteophyte. In particular, it is worth emphasising that osteophyte seems to be strongly associated with pain when it is present at any site, whereas the association of pain with narrowing is strong only at the lateral PFJ or medial TFJ. For narrowing at the PFJ, this might be explained by the fact that when the lateral facet is narrowed, the medial facet may become paradoxically widened. Some support for this comes from the finding that there is an increasing association with pain at 
increasing medial facet joint space widths above $6 \mathrm{~mm}$.

Our results differ slightly from those recently reported from the Framingham Osteoarthritis Study. ${ }^{7}$ By using a recursive partitioning analysis of one random knee from each participant, this study reported a definition that included either $\geqslant$ grade 2 osteophyte or $\geqslant$ grade 2 joint space narrowing and either $\geqslant$ grade 1 sclerosis, cyst or osteophyte present in the same compartment to be better at differentiating subjects with or without OA than osteophytes alone. In the atlas used in this study, a grade 2 osteophyte corresponds roughly to a grade 1 osteophyte in other atlases. ${ }^{19} 25$ There are at least two possible reasons why our results differ. The Framingham study used lateral radiographs to assess the PFJ; these provide a different and less reproducible assessment than skyline views. ${ }^{8926}$ Additionally, a different definition of knee pain was used that required the presence of crepitus, a physical sign that has relatively poor reproducibility. ${ }^{27}$ In our analysis of the association between pain and structural change we have chosen to select for analysis only one knee from each subject, that which showed the greatest structural change for the feature under consideration - that is, the worst knee. We accept that by collecting data on pain at the person level, rather than at the level of each knee, that it is possible that the side of pain and the side of greatest radiographic change may not be the same and that the side of greatest radiographic change may be different for osteophyte and narrowing. However, there is no reason to suppose that either radiographic feature, that is joint space narrowing or osteophyte, would be preferentially biased by this mode of analysis.

The exact performance of osteophyte in defining knee OA varies according to joint site. The presence of $\geqslant$ grade 1 osteophyte at the $\mathrm{PFJ}$ is more sensitive but less specific than at the TFJ, although efficiency is similar at each site. Inclusion of patellofemoral assessment increases sensitivity from $38.1 \%$ to $62.3 \%$. This finding, which accords with one previous study, ${ }^{24}$ emphasises that adequate radiographic assessment of both these compartments is required in community studies. While the Framingham study reported that the inclusion of PFJ assessment resulted in only a modest increment in sensitivity above that obtained from TFJ assessment alone, ${ }^{7}$ this difference might be explained by their use of lateral rather than skyline views.

The importance of osteophyte in radiographic definition at the knee does not extend to other joint sites. For example, joint space narrowing at the hip is clearly a better predictor of pain than osteophyte ${ }^{12}$ and joint space width measurement has been proposed as the best method to use for disease definition in the community. Indeed, the presence of isolated osteophyte at the hip is of uncertain significance. ${ }^{28}$ There may be several reasons for this apparent discrepancy between definition at these large lower limb joints. It may simply be a reflection that joint space is more reliably assessed at the hip than at the knee. There is some evidence for this, with joint space narrowing in the lateral tibiofemoral compartment reported to be particularly difficult to assess. ${ }^{4}$ Despite using metered callipers in this study, which give accurate and reproducible measurements, the performance of definitions based on joint space narrowing remains less than osteophyte. This suggests that the role of different radiographic features in producing symptoms is genuinely fundamentally different at these two sites. It is still possible, however, that other more precise methods of assessment, such as flouroscopic joint positioning and macroradiography, might change the performance of narrowing. ${ }^{29}{ }^{30}$

In conclusion, the results of this study suggest that the presence of osteophyte is the best predictor of knee pain among men and women in the community and that direct measurement of joint space does not confer any advantage over grading. Joint space width does not decrease with age among asymptomatic subjects and there does not seem to be a biological threshold for joint space width, below which the likelihood of symptoms markedly increases. The discordant associations between individual radiographic features and symptoms at the hip and knee is further evidence that each joint site justifies separate consideration in the assessment of OA.

As Michael Doherty is the editor of the journal, Professor Peter Croft served as acting editor to ensure the impartial review of this paper.

We are indebted to the Arthritis and Rheumatism Council for financial support.

1 Petersson I. Occurrence of osteoarthritis of the peripheral oints in European populations. Ann Rheum Dis 1996;55:659-64.

2 Spector TD, Hart DJ. How serious is knee osteoarthritis? Ann Rheum Dis 1992;51:1105-6.

3 Kellgren JH, Lawrence JS. The epidemiology of chronic rheumatism: atlas of standard radiographs. Oxford: Blackwell Scientific Publications, 1963

4 Spector TD, Hart DJ, Harris PA, Dacre JE, Doyle DV. Definition of osteoarthritis of the knee for epidemiological nition of osteoarthritis of the knee for
studies. Ann Rheum Dis 1993;52:790-4.

5 Altman RD, Asch E, Bloch D, Bole G, Borenstein D, Brandt $\mathrm{K}$, et al. Development of criteria for the classification and reporting of osteoarthritis: classification of osteoarthritis of reporting of osteoarthritis: classification of oste
the knee. Arthritis Rheum 1986;29:1039-49.

the knee. Arthritis Rheum 1986;29:1039-49.
6 McAlindon TE, Snow S, Cooper C, Dieppe PA. Radiographic patterns of osteoarthritis of the knee joint in the community: the importance of the patellofemoral joint. Ann Rheum Dis 1992;51:844-9.

7 Felson DT, McAlindon TE, Anderson J, Naimark A, Weissman BN, Aliabadi $\mathrm{P}$, et al. Defining radiographic osteoarthritis of the whole knee. Osteoarthritis Cartilage 1997;5: $241-50$

8 Jones AC, Ledingham J, McAlindon TE, Regan M, Hart DJ, MacMillan PJ, et al. Radiographic assessment of patellofemoral osteoarthritis. Ann Rheum Dis 1993;52:655-8.

Cicuttini FM, Baker J, Hart DJ, Spector TD. Choosing the best method for radiological assessment of patellofemoral
osteoarthritis. Ann Rheum Dis 1996;55:134-6.

10 Bagge E, Bjelle A, Eden S, Svanborg A. Factors associated with radiographic arthritis: Results from the population with radiographic arthritis: Results from the population study of 70-year-old

11 Croft P, Cooper C, Wickham C, Coggon D. Defining osteoarthritis of the hip for epidemiologic studies. Am J Epidemiol 1990;132:514-22.

12 Croft P, Cooper C, Coggon D. Case definition of hip osteoarthritis in epidemiologic studies. J Rheumatol 1994; 21:591-2.

13 Jorring K. Osteoarthritis of the hip. Acta Orthop Scand 1980;51:523-30.

14 Danielsson L. Incidence and prognosis of coxarthrosis. Acta Orthop Scand Suppl 1964;66:1-114.

5 Danielsson L, Lindberg H, Nilsson B. Prevalence of coxarthrosis. Clin Orthop Rel Res 1984;191:110-15.

16 Dacre JE, Scott DL, Da Silva JA, Welsh G, Huskisson EC. Joint space in radiologically normal knees. Br J Rheumatol 1991;30:426-8.

17 O'Reilly S, Muir K, Doherty M. Screening for knee pain in osteoarthritis: which question? Ann Rheum Dis 1996;55: 931-3. 
18 Laurin C, Dussault R, Levesque H. The tangential X-ray investigation of the patellofemoral joint. Clin Orthop Rel Res 1979;144:16-2

19 Altman RD, Hochberg MC, Murphy WA, Wolfe F. Atlas of individual radiographic features in osteoarthritis. Osteoarthritis Cartilage 1995;3:3-70.

20 Buckland-Wright JC. Protocols for precise radio-anatomical positioning of the tibiofemoral and patellofemoral compartments of the knee. Osteoarthritis Cartilage 1995;3:7180.

21 Cohen J. A coefficient of agreement for nominal scales. Educational and Psychological Measurement 1960;20:37-46.

22 Bland J, Altman DG. Statistical methods for assessing agreement between two methods of clinical assessment. Lancet 1986;i:307-10.

23 Altman DG. Practical statistics for medical research. London: Chapman and Hall, 1991.

24 Cicuttini FM, Baker J, Hart DJ, Spector TD. Association of pain with radiological changes in different compartments pain with radiological changes in different compartments
and views of the knee joint. Osteoarthritis Cartilage 1996;
4:143-7.

25 Spector TD, Cooper C, Cushnaghan J, Hart DJ, Dieppe PA. $A$ radiographic atlas of knee osteoarthritis. London: Springer Verlag, 1992.

26 Lanyon P, Jones A, Doherty M. Assessing progression of patellofemoral osteoarthritis: a comparison between two radiographic methods. Ann Rheum Dis 1996;55:875-9.

27 Jones A, Hopkinson N, Pattrick M, Berman P, Doherty M. Evaluation of a method for clinically assessing osteoarthritis of the knee. Ann Rheum Dis 1992;51:243-5.

28 Nevitt M. Definition of hip osteoarthritis for epidemiological studies. Ann Rheum Dis 1996;55:652-5.

29 Buckland-Wright JC, Macfarlane DG, Williams SA, Ward RJ. Accuracy and precision of joint space width measurements in standard and macroradiographs of osteoarthritic knees. Ann Rheum Dis 1995;54:872-80.

30 Buckland-Wright JC, Macfarlane DG, Williams S, Ward R. Joint space width measured more accurately and precisely Joint space width measured more accurately and precisely
in semiflexed than extended views of OA knees. Br J Rheumatol 1995;34:121.

\section{Historical images}

Series editors: W Grassi, C Cervini

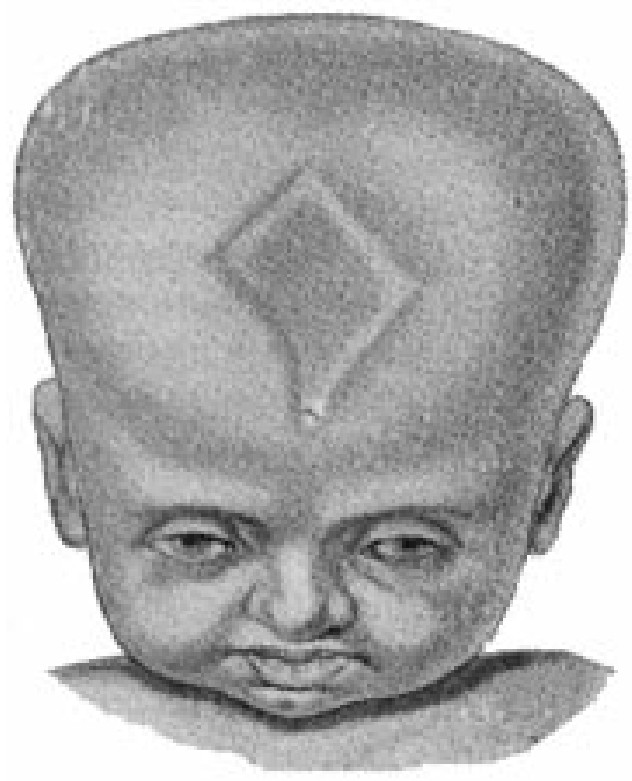

Figure 11 Rickets.

Skull deformity (widening of sutures and abnormal parietal and frontal bossing) in a 2 year old child. Marfan A-B.

Rachitisme (osteo-lymphatisme de l'enfance). In: Marfan A-B, Apert, Aviragnet, Bernard L, Garnier M, Hallé $\mathcal{F}$, Milian. Maladies des os. Paris: Librairie f-B Baillière et fils, 1912. 